\title{
Low serum copper and zinc concentrations in North Indian children with overweight and obesity
}

\author{
Niskie stężenie miedzi i cynku w surowicy u dzieci z północnej Indii z nadwagą i otyłością
}

\author{
1,2Vivek Singh Malik, ${ }^{2}$ Devi Dayal, ${ }^{1}$ Ravindra Khaiwal, ${ }^{2}$ Bhavneet Bharti, ${ }^{2}$ Anil Bhalla, \\ ${ }^{2}$ Satwinder Singh, ${ }^{2}$ Harvinder Kaur, ${ }^{2}$ Savita Verma Attri
}

${ }^{1}$ Department of Community Medicine and School of Public Health, Chandigarh, India

${ }^{2}$ Department of Paediatrics, Post Graduate Institute of Medical Education and Research, Chandigarh, India

\begin{abstract}
Introduction: There are limited data on the alterations of serum copper and zinc, which have been proposed to have associations among children with obesity.

Material and methods: A total of 173 children were enrolled and grouped into overweight/obese $(n=69)$ and non-obese $(n=104)$ according to CDC 2000 growth charts. Serum and whole blood zinc and copper concentrations were measured by validated ICP-MS method, and copper/zinc ratios were calculated and correlated to various anthropometric parameters.

Results: Mean BMI in obese $(24.78 \pm 3.93)$ was significantly higher as compared to non-obese $(16.44 \pm 2.34 ; p<0.0001,95 \% \mathrm{Cl}$ : 15.9873-16.8998) children. Mean serum copper levels in obese children (1099.80 $\pm 478.67 \mu \mathrm{g} / \mathrm{l})$ were significantly lower than for non-obese children $(2063.77 \pm 1006.81 \mu \mathrm{g} / \mathrm{l} ; p=0.0001,95 \% \mathrm{Cl}: 1867.9755-2259.5755)$. Similarly, the mean serum zinc levels in obese children $(851.53 \pm 406.33 \mu \mathrm{g} / \mathrm{l})$ were also significantly lower as compared to non-obese children $(1528.72 \pm 796.82 \mu \mathrm{g} / \mathrm{l}$; $p=0.0001,95 \% \mathrm{Cl}: 1373.76-1683.6879)$. Mean whole blood copper levels were significantly lower in obese (929.56 $\pm 200.15 \mu \mathrm{g} / \mathrm{l})$ as compared to non-obese (1393.22 $\pm 861.92 \mu \mathrm{g} / \mathrm{l} ; p=0.0001,95 \% \mathrm{Cl}$ : 1225.6023-1560.8481) children. Similarly, the mean whole blood zinc levels in obese (4384.11 $\pm 881.87 \mu \mathrm{g} / \mathrm{l})$ were also significantly lower as compared to non-obese $(5380.14 \pm 2236.77 \mu \mathrm{g} / \mathrm{l}$; $p=0.001,95 \% \mathrm{Cl}: 4945.1491-5815.1416)$ children.

Conclusions: The serum and whole blood concentrations of zinc and copper were found to be significantly lower in children with exogenous obesity as compared to controls. Additional investigations are recommended to see the underlying aspect of these elements in the development of obesity along with their co-morbidities.
\end{abstract}

Key words:

serum, whole blood, copper, zinc, ratio, childhood obesity. 


\section{Introduction}

The worldwide increase in the occurrence of overweight and obesity has become a serious community health concern over the last several decades [1]. In addition to genetic, environmental, and lifestyle risk factors, toxic metals are presumed to show major contributing factors to overweight/obesity by influencing many features of metabolism, e.g. by inducing oxidative stress or by displacing vital metals that may affect metabolic processes, carbohydrate tolerance, and energy production [2]. Several toxic metals such as cobalt, barium, mercury, cadmium, caesium, lead, molybdenum, and thallium have a relationship with waist circumference and body mass index [3]. These relationships suggest that environmental exposure to these metallic elements may play a role in the altered weight gain or loss in humans [3]. Aggregate exposure to metals is associated with overweight/obesity and its associated comorbidities, such as diabetes and hypertension [4].

Studies on the role of zinc in the regulation of metabolic syndrome, cytokine expression, activation of antioxidant enzymes by reducing the oxidative stress, and suppressing inflammatory response have been reported; similarly, zinc supplementation has been reported to improve blood pressure, LDL cholesterol, and glucose levels [5].

A healthy lifestyle and educational activities should be encouraged among school children and adults encouraging them to adopt and follow a healthy diet pattern and reduce the risks of being overweight/obese, which may have dangerous health consequences in later life [6]. Recent data also indicate that toxic exposure not only to heavy metals but also to copper is associated with an increased risk of cardiovascular disease and coronary heart disease [7]. In mice, deficiency of zinc caused by a mutation in Znt7, a zinc transporter, led to a decrease in the accumulation of body fat and consequently decreased body weight, whereas deficiency of copper caused the development of adiposity [8]. Alterations in the serum concentrations of copper and zinc have been documented in children and teenagers with overweight/obesity [9]. However, data on the relationship between metal exposure and the anthropometric indices is inconsistent and limited in developing countries, due to poor regulatory mechanisms despite higher environmental exposure.

The present study was designed to find the relationship between two essential metals, copper and zinc, and various anthropometric indices in children with exogenous obesity.

\section{Material and methods}

A total of 173 healthy children aged 6-16 years were enrolled and grouped into overweight/obese $(n=69)$ and nonobese ( $n=104)$ according to CDC 2000 growth charts. The physical assessments included measurement of weight to the nearest $50 \mathrm{~g}$ on an electronic weighing machine and height to the nearest $1 \mathrm{~mm}$ with a stadiometer. Body mass index (BMI) was expressed as $\mathrm{kg} / \mathrm{m}^{2}$. Waist and hip circumference (WC and $\mathrm{HC}$ ) were measured by using standardised anthropometric techniques to the adjacent $0.1 \mathrm{~cm}$, and the WHR (waist/hip ratio) was calculated. Children with BMI $>85^{\text {th }}-<95^{\text {th }}$ percentiles, classified as overweight, and $\mathrm{BMI}>95^{\text {th }}$ percentiles, classified as obese, were grouped together, and children with $\mathrm{BMI}>5^{\text {th }}$ $-<85^{\text {th }}$ percentiles were considered as non-obese. Those having diabetes or hypertension, hyperlipidaemia, secondary obesity, infection, hereditary or inflammatory disease, and intake of medications were excluded from the study. Written consent was obtained from parents or primary caregivers and assent from the child was taken before inclusion, which was approved by the Institutional Ethics Committee (PGI/IEC/2015/870). All the measures followed during the study adhered to the Helsinki Declaration of 1975, as revised in 2008.

Laboratory assessment included an analysis of metals by validated ICP-MS (Inductively Coupled Plasma Mass Spectrometry) multi-elementary method. Agilent 7700x ICP-MS with collision cell technology was used, which operates in a helium collision mode to remove all polyatomic interferences. High-purity (> 99.9\%) argon gas was used in the plasma torch. Water was purified with a Q-POD Element system, Millipore (Elix Technology). Suprapure nitric acid (Sigma Aldrich), multielement calibration standard, gold standard (Agilent Technologies), and hydrogen peroxide solution (30\% purified) were obtained from Merck. The quality assessment was done by participating in the LAMP (Lead and multi-element proficiency) testing of CDC, National Centre for Environmental Health (Atlanta USA). Whole blood and serum $(0.2 \mathrm{ml})$ multielement analysis was performed after the addition of $2 \mathrm{ml}$ of nitric acid and $0.5 \mathrm{ml}$ of $\mathrm{H}_{2} \mathrm{O}_{2}$ and $10 \mu \mathrm{g} / \mathrm{l}$ of gold solution followed by microwave digestion (parameters: power 29-1800 V, ramp time 20 minutes, hold time 15 minutes, and temperature $200^{\circ} \mathrm{C}$ ). The final volume was made with metal-free water up to $10 \mathrm{ml}$. A calibration curve plotted each time before sample analysis ranged from $00 \mu \mathrm{g} / \mathrm{l}$ to $200 \mu \mathrm{g} / \mathrm{l}$. The serum and whole blood concentration of metals were expressed as $\mu \mathrm{g} / \mathrm{l}$.

\section{Statistical analysis}

An excel spreadsheet was created to determine the mean and SD from the data. Analysis of variance (ANOVA) and correlation (Pearson's) analysis was done to determine if there were any statistically significant differences in serum and whole blood mean copper, zinc levels, zinc/copper, and copper/zinc ratios between obese and non-obese children. $P$-value was calculated for each variable using SPSS-16.0 (Chicago, IL, USA). The level was considered statistically significant if the $p$-value was less than 0.05

\section{Results}

The study comprised 69 obese and 104 non-obese children. Their anthropometric characteristics, glucose, and lipid profiles are presented in Tables I and II, respectively. The mean 
levels of serum copper and zinc were significantly low in overweight/obese as compared to non-obese children. The low levels of copper were also observed in whole blood samples; however, no significant differences were observed in serum copper/zinc ratios amongst overweight/obese and non-obese children (Table III).

Table I. Baseline characteristics of the study population

\begin{tabular}{llll}
\hline Variables & Overweight/Obese $(n=69)$ & Non obese $(n=104)$ & $P$ value \\
\hline Age $($ years $)$ & $10.97 \pm 1.93$ & $9.88 \pm 2.13$ & 0.001 \\
\hline BMl $\left(\mathrm{kg} / \mathrm{m}^{2}\right)$ & $24.78 \pm 3.93$ & $16.44 \pm 2.34$ & $<0.0001$ \\
\hline WC $(\mathrm{cm})$ & $79.04 \pm 10.11$ & $55.11 \pm 11.33$ & $<0.0001$ \\
\hline HC $(\mathrm{cm})$ & $83.66 \pm 10.90$ & $62.45 \pm 12.90$ & $<0.0001$ \\
\hline WHR & $0.95 \pm 0.15$ & $0.88 \pm 0.05$ & $<0.0001$ \\
\hline
\end{tabular}

$\mathrm{BMI}$ - body mass index; WC - waist circumference; HC - hip circumference, and waist: hip ratio (WHR)

Table II. Serum concentrations of glucose and lipid profile

\begin{tabular}{llll}
\hline Variables & Overweight/Obese $(n=69)$ & Non obese $(n=104)$ & $P$ value \\
\hline Glucose & $94.43 \pm 18.22$ & $72.91 \pm 18.62$ & $<.0001$ \\
\hline Cholesterol & $157.78 \pm 35.29$ & $144.43 \pm 32.39$ & 0.011 \\
\hline HDL & $44.84 \pm 10.27$ & $44.76 \pm 15.78$ & 0.970 \\
\hline LDL & $85.16 \pm 32.78$ & $76.25 \pm 26.93$ & 0.028 \\
\hline TG & $138.87 \pm 67.25$ & $117.05 \pm 60.47$ & 0.53 \\
\hline
\end{tabular}

HDL - high density lipoproteins; LDL - low density lipoproteins; TG - triglycerides

Table III. Serum and whole blood concentrations of zinc, copper and their ratios among study children

\begin{tabular}{|c|c|c|c|}
\hline Metals $(\mu \mathrm{g} / \mathrm{l})$ & Overweight/Obese (Mean \pm SD) & Non-obese (Mean \pm SD) & $P$ value \\
\hline \multicolumn{4}{|l|}{ Serum } \\
\hline Copper & $1099.80 \pm 478.67$ & $2063.77 \pm 1006.81$ & $<0.0001$ \\
\hline Zinc & $851.53 \pm 406.33$ & $1528.72 \pm 796.82$ & $<0.0001$ \\
\hline Copper : Zinc ratio & $1.32 \pm 0.33$ & $1.51 \pm 0.85$ & 0.083 \\
\hline \multicolumn{4}{|l|}{ Whole blood } \\
\hline Copper & $929.56 \pm 200.15$ & $1393.22 \pm 861.92$ & $<0.0001$ \\
\hline Zinc & $4384.11 \pm 881.87$ & $5380.14 \pm 2236.77$ & 0.001 \\
\hline Copper : Zinc ratio & $0.21 \pm 0.04$ & $0.25 \pm 0.12$ & 0.012 \\
\hline
\end{tabular}


Amongst children with obesity, BMl showed a negative correlation with whole blood $\mathrm{Cu} / \mathrm{Zn}$ ratio $(r=-0.331, p=0.01)$. Negative correlation was also observed between cholesterol and whole blood $\mathrm{Cu}(r=-0.376, p=0.01)$ and $\mathrm{Cu} / \mathrm{Zn}$ ratio $(r=-0.278, p=0.05)$.

\section{Discussion}

Obesity is considered to have significant associations with deficiency as well as an excess of metallic elements [9]. However, the exact role of deficiency or excess of these metals concerning obesity and its comorbid conditions is still unclear [10]. Moreover, there is limited information on their role in childhood obesity [9]. Our cross-sectional study is one of the few available studies to examine the association between metals and obesity.

The main finding of our study was that the mean serum levels, as well as whole blood concentrations of $\mathrm{Cu}$ and $\mathrm{Zn}$, were significantly low in children with overweight/obesity. These results are in partial contrast to previous data, which found low levels of zinc but high levels of copper in children with obesity $[7,9]$. Several studies have consistently reported low zinc levels in obesity [7, 9-12]. However, Weisstaub et al. conducted a study in preschool children and did not find any relationship between serum zinc levels and body weight [13]. As an essential element, zinc is involved in several biochemical reactions such as protein synthesis, insulin action, and antioxidant processes [9]. Higher abdominal fat was shown to be associated with low levels of zinc [14].

Many studies have reported a relationship between zinc and metabolic syndrome - significantly lower zinc levels have been reported in obese patients $[15,16]$; similarly lower $\mathrm{Zn}$ in obese people is associated with insulin resistance, altered lipid profile, and inflammation as a metabolic disturbing factor [17]. Lower zinc levels have been reported in diabetic patients as compared to their healthy counterparts [18-24]. In adolescents, lower zinc intake has been associated with higher concentration of insulin [25]. The role of zinc in oxidative stress in obese mice has been studied, revealing that zinc works as a cofactor of an antioxidant enzyme of $\mathrm{Cu}$ [26]. Zinc regulates the proinflammatory cytokine expression [27], in which white adipose tissue produces interleukin- 6 stimulating the secretion

\section{References}

1. Aggarwal B, Jain V. Obesity in Children: Definition, Etiology and Approach. Indian J Pediatr 2018; 85: 463-471. doi: 10.1007/s12098017-2531-x

2. Satarug S, Moore MR. Adverse health effects of chronic exposure to low-level cadmium in foodstuffs and cigarette smoke. Environ Health Perspect 2004; 112: 1099-1103. doi: 10.1289/ehp.6751

3. Wang X, Mukherjee B, Park SK. Associations of cumulative exposure to heavy metal mixtures with obesity and its comorbidities of CRP (C-reactive protein) in liver [28]. Zinc influences the expression of PPARs- $\alpha$ (peroxisome proliferator-activated receptors $\alpha$ ), which plays a key role in the glucose and lipoprotein metabolism [29, 30]. Zinc supplementation has been reported to decrease the total cholesterol, LDL cholesterol, and triglycerides and increase the HDL cholesterol $[26,31]$. Experimental studies suggest adequate $\mathrm{Zn}$ status for normal functioning of adipocytes and leptin synthesis [32]. Depletion of zinc has a negative impact on insulin sensitivity and glucose tolerance [33]. In diabetic patients zinc supplementation has been reported to improve the glucose homeostasis [34] by stimulating glycolysis and glucose transportation in adipocytes, and via inhibition of gluconeogenesis [35].

Additionally, the low Zn-a2-glycoprotein gene expression in obese individuals may contribute to the obesity progression linked with lower serum adiponectin levels and higher levels of plasma leptin [9]. Further larger studies are therefore needed to investigate the role of $\mathrm{Zn}$ levels in obesity development, as well as whether zinc supplementation may show some beneficial effects in obesity.

As compared to zinc, the role of copper in the various disease processes including obesity and metabolic disorders is less well elucidated. Copper as an antioxidant enzyme works against free radicals to protect the organism against oxidative stress [36]. An increase in copper levels in children with obesity has been noted in previous studies [9, 37]. However, copper levels were found to be significantly low in our study. Copper deficiency has been suggested to contribute to cardiovascular disease, which is a known consequence of obesity, through abnormalities in glucose tolerance, blood pressure control, and lipid metabolism [36].

\section{Conclusions}

This study demonstrates low levels of copper and zinc in serum as well as whole blood in children with overweight/obesity. Our findings suggest that while measuring BMI among obese children, monitoring of serum copper and zinc levels should be done in order to avoid deficiency problems. We suggest larger studies to elucidate the role of these essential metals in the development of obesity and their associated co-morbidities. and metabolic syndrome: A cross-sectional analysis of the National Health and Nutrition Examination Survey 2011-2014. Environ Res 2019; 168: 397-405.

5. Olechnowicz J, Tinkov A, Skalny A, Suliburska J. Zinc status is associated with inflammation, oxidative stress, lipid, and glucose metabolism. J Physiol Sci 2018; 68: 19-31. doi: 10.1007/s12576017-0571-7. 
6. Drewa A, Zorena K. Prevention of overweight and obesity in children and adolescents in European countries. Pediatr Endocrinol Diabetes Metab 2017; 23: 152-158. doi: 10.18544/PEDM-23.03.0087

7. Chowdhury R, Ramond A, O'Keeffe LM, et al. Environmental toxic metal contaminants and risk of cardiovascular disease: systematic review and meta-analysis. BMJ 2018; 362: k3310. doi: 10.1136/ bmj.k3310

8. Fukunaka A, Fujitani Y. Role of Zinc Homeostasis in the Pathogenesis of Diabetes and Obesity. Int J Mol Sci 2018; 19: pii: E476.

9. Fan Y, Zhang C, Bu J. Relationship between Selected Serum Metallic Elements and Obesity in Children and Adolescent in the U.S Nutrients 2017; 9: pii: E104.

10. García OP, Long KZ, Rosado JL. Impact of micronutrient deficiencies on obesity. Nutr Rev 2009; 67: 559-572.

11. Di Martino G, Matera MG, De Martino B, et al. Relationship between zinc and obesity. J Med 1993; 24: 177-183.

12. Marreiro DN, Fisberg M, Cozzolino SM. Zinc nutritional status in obese children and adolescents. Biol Trace Elem Res 2002; 86: 107-122.

13. Weisstaub G, Hertrampf E, López de Romaña D, et al. Plasma zinc concentration, body composition and physical activity in obese preschool children. Biol Trace Elem Res 2007; 118: 167-174. doi: 10.1007/s12011-007-0026-8

14. Singh RB, Beegom R, Rastogi SS, et al. Association of low plasma concentrations of antioxidant vitamins, magnesium and zinc with high body fat per cent measured by bioelectrical impedance analysis in Indian men. Magnes Res 1998; 11: 3-10.

15. Freitas EP, Cunha AT, Aquino SL, et al. Zinc status biomarkers and cardiometabolic risk factors in metabolic syndrome: a case control study. Nutrients 2017; 9: 175.

16. Suliburska J, Cofta S, Gajewska E, et al. The evaluation of selected serum mineral concentrations and their association with insulin resistance in obese adolescents. Eur Rev Med Pharmacol Sci 2013; 17: 2396-2400

17. Costarelli L, Muti E, Malavolta M, et al. Distinctive modulation of inflammatory and metabolic parameters in relation to zinc nutritional status in adult overweight/obese subjects. J Nutr Biochem 2010; 21: 432-437. doi: 10.1016/j.jnutbio.2009.02.001

18. Sinha S, Sen S. Status of zinc and magnesium levels in type 2 diabetes mellitus and its relationship with glycemic status. Int J Diabetes Dev Ctries 2014; 34: 220-223. doi: https://doi.org/10.1007/ s13410-014-0196-9

19. Olaniyan OO, Awonuga MA, Ajetunmobi AF, et al. Serum copper and zinc levels in Nigerian type 2 diabetic patients. African Journal of Diabetes Medicine 2012; 20: 36-38.

20. Devi TR, Hijam D, Dubey A i wsp. Study of serum zinc and copper levels in type 2 diabetes mellitus. Int J Contemp Med Res 2016; 3 : 1036-1040

21. Kaur J, Singh T. Estimation of serum magnesium and zinc levels in type-2 diabetes mellitus. Int J Bioassays 2015; 4: 3654-3656.
22. Yahya $H$, Yahya KM, Saqib A. Minerals and type 2 diabetes mellitus - level of zinc, magnesium and chromium in diabetic and non diabetic population. J Univer Med Dent College 2011; 2: 34-38.

23. Jyothirmayi B, Vasantha M. Study of zinc and glycated $\mathrm{Hb}$ levels in diabetic complications. Int J Pharm Clin Res 2015; 7: 360-363.

24. Kumar DA, Priya VS, Jaiprabhu J, Ramalingam K. Serum copper and zinc levels significance in type 2 diabetic patients. J Med Sci Tech 2014; 3: 79-81.

25. Ho M, Baur LA, Cowell CT, et al. Zinc status, dietary zinc intake and metabolic risk in Australian children and adolescents; Nepean Longitudinal Study. Eur J Nutr 2017; 56: 2407-2414. doi: 10.1007/ s00394-016-1280-3

26. Li HT, Jiao M, Chen J, Liang Y. Roles of zinc and copper in modulating the oxidative refolding of bovine copper, zinc superoxide dismutase. Acta Biochim Biophys Sin (Shanghai) 2010; 42: 183-194. doi: 10.1093/abbs/gmq005

27. Haase H, Rink L. Zinc signals and immune function. Biofactors 2014; 40: 27-40. doi: 10.1002/biof.1114

28. Jung S, Kim MK, Choi BY. The relationship between zinc status and inflammatory marker levels in rural Korean adults aged 40 and older. PLoS One 2015; 10: e0130016. doi: 10.1371/journal.pone.0130016

29. Löffek S, Schilling O, Franzke CW. Biological role of matrix metalloproteinases: a critical balance. Eur Respir J 2011; 38: 191-208. doi: 10.1183/09031936.00146510

30. Usmanova ZA. Relationship between the levels of mmp-9, timp-1, and zinc in biological samples of patients with carotid atherosclerosis. Int J Biomed 2015; 5: 60-64. doi: 10.21103/article5(2) cr2

31. El-Ashmony SM, Morsi HK, Abdelhafez AM. Effect of zinc supplementation on glycemic control, lipid profile, and renal functions in patients with type II diabetes: a single blinded, randomized, placebo-controlled, trial. J Biol Agric Health 2012; 2: 33.

32. Baltaci AK, Mogulkoc R. Leptin and zinc relation: in regulation of food intake and immunity. Indian J Endocrinol Metab 2012; 16 (Suppl 3): S611. doi: 10.4103/2230-8210.105579

33. Yang HK, Lee SH, Han K, et al. Lower serum zinc levels are associated with unhealthy metabolic status in normal-weight adults: the 2010 Korea National Health and Nutrition Examination Survey. Diabetes Metab 2015; 41: 282-290. doi: 10.1016/j.diabet.2015.03.005

34. Jayawardena R, Ranasinghe P, Galappatthy P, et al. Effects of zinc supplementation on diabetes mellitus: a systematic review and meta-analysis. Diabetol Metab Syndr 2012; 4: 13. doi: 10.1186/17585996-4-13

35. Ranasinghe P, Pigera S, Galappatthy P, et al. Zinc and diabetes mellitus: understanding molecular mechanisms and clinical implications. Daru 2015; 23: 44. doi: 10.1186/s40199-015-0127-4

36. Klevay LM. Cardiovascular disease from copper deficiency - a history. J Nutr 2000; 130 (2S Suppl): 489S-492S. doi: 10.1093/jn/130.2.489S.

37. Yakinci $C$, Paç $A$, Küçükbay $F Z$, et al. Serum zinc, copper, and magnesium levels in obese children. Acta Paediatr Jpn 1997; 39: 339-341. doi: 10.1111/j.1442-200x.1997.tb03748.x 